\title{
Comparative Performance of Various PV Technologies in Different Italian Locations
}

\author{
A. Colli ${ }^{1, *}$, M. Marzoli ${ }^{2}$, W. Zaaiman ${ }^{3}$, S. Guastella ${ }^{2}$, W. Sparber ${ }^{1}$ \\ ${ }^{1}$ EURAC Research, Institute for Renewable Energy, Bolzano, Italy. \\ ${ }^{2}$ Ricerca sul Sistema Energetico - RSE S.p.A., Milano, Italy. \\ ${ }^{3}$ EC Joint Research Centre, Institute for Energy, Renewable Energy Unit, Ispra (VA), Italy. \\ * Corresponding author. Tel: +39 0471 055630, Fax: +39 0471 055699, E-mail: alessandra.colli@eurac.edu
}

\begin{abstract}
With the increasing number of photovoltaic (PV) installations on a worldwide scale, an outdoor performance analysis of various types of modules is needed. The purpose to assess and compare the performance of different types of modules in specific geographical locations, under various climatic conditions and to identify benefits/losses given by a specific surrounding context, is very important to evaluate the energetic behavior of future installations and direct them toward the most suitable technology to apply. The installations taken into consideration are located in Bolzano, Milan, and Catania, allowing comparison among three different Italian climate conditions and irradiance levels: the Alpine region, the upper Padana valley, and the see-side area in Sicily. In Bolzano, a multi-technology ground-mounted PV field is taken into analysis. For Milan and Catania, two multi-section PV power plants are monitored. The monitoring activities are done taking the international norm IEC 61724 as reference document, together with the best practice already existing in the field. The PV modules are evaluated in relation to ambient conditions, installation characteristics, module-specific behavior and state. Results are provided in a comparative way among the three considered geographical locations. Results are validated and an uncertainty estimation is shown. As instrumentation and environmental conditions are not the same, uncertainties for the locations might be different. Possible issues related to monitoring activities, as well as the performance of different PV technologies, will be highlighted.
\end{abstract}

Keywords: Monitoring, PV System Performance, Energy Rating, Site-Dependent Performance Ratio.

\section{Introduction}

The number of photovoltaic (PV) installations in Italy is quickly increasing, thanks to the national "Conto Energia" programme. An increasing trend has been also registered at European level, as well as worldwide. In this context, a detailed monitoring of selected PV plants and the analysis of operational data of these plants is needed to support a realistic outdoor performance analysis of various types of modules in specific geographical environments. This action supports both the scientific community and the different actors in the PV environment, such as developers, producers, installers, financing institutions, as well as decision-makers and customers.

\section{The PV installations}

The installations taken into consideration in this work are located in Bolzano, Milan, and Catania, allowing comparison among three different Italian climate conditions and irradiance levels: the Alpine region, the upper Padana valley, and the see-side area in Sicily. The evaluation has been limited to two months (September and October 2010) due to the recent operation activity of the installation located in Bolzano. From the different locations, four PV technologies are analyzed and evaluated: back-contact monocrystalline silicon cells (BC m$\mathrm{Si}$ ), heterojunction cells with intrinsic thin layer (HIT), copper indium gallium selenide (CIGS) and cadmium telluride (CdTe). All groups are mounted on $30^{\circ}$-tilted supports.

It must be stressed that the monitoring systems are, at the moment, different for Bolzano (supervised by EURAC Research and reading electrical data through the inverter system, with an SMA amorphous silicon reference device) in comparison with the installations of Milan and Catania (supervised by RSE and adopting a dedicated electrical monitoring system, using 
a crystalline silicon reference device from the type EstiSensor [1]). This leads to differences in the acquired data, which are visible in their representation, but are also discussed and justified along the paper to make the comparison possible and valuable. A validation of the results of the performance ratio (PR) among the different groups, locations and monitoring systems is done in Section 4.

\subsection{Airport of Bolzano Dolomiti (ABD) PV field}

The multitechnology ground-mounted grid-connected PV field at the Airport of Bolzano Dolomiti (ABD), in the North-East of Italy, is in operation since August 10, 2010 and has a total peak power of $724 \mathrm{kWp}$. It is divided into two main parts: a $662 \mathrm{kWp}$ commercial installation, mounting $8538 \mathrm{CdTe}$ modules, and a $62 \mathrm{kWp}$ experimental installation, mounting 24 different types of modules, divided into groups ranging between 1 and $2 \mathrm{~kW}$ each. The groups selected for the analysis are listed in Table 1. Results for two CIGS and two BC m-Si groups are shown, to highlight possible differences among the same product. For the commercial field using CdTe modules the monitoring results for a single inverter has been considered, connecting a total of 120 modules divided into 20 strings of 6 modules each. Figure 1 and 2 show the instantaneous PR for the four PV technologies calculated on a 15minute base for each day of the month, respectively for September and October 2010.

Table 1. Groups and characteristics from ABD PV field in Bolzano.

\begin{tabular}{ccccc}
\hline Group & Type & kWp & Inverter & Overview \\
\hline E2 & HIT & 3.87 & SB4000TL-20 & \\
E10 & CIGS & 1.12 & SB1100 & SB1100 \\
E11 & CIGS & 1.12 & SB1100 & \\
E14-A & BC m-Si & 1.2 & SB1100 & \\
E14-B & BC m-Si & 1.2 & SMC9000TL-10 \\
Commercial & CdTe & 9.3 &
\end{tabular}

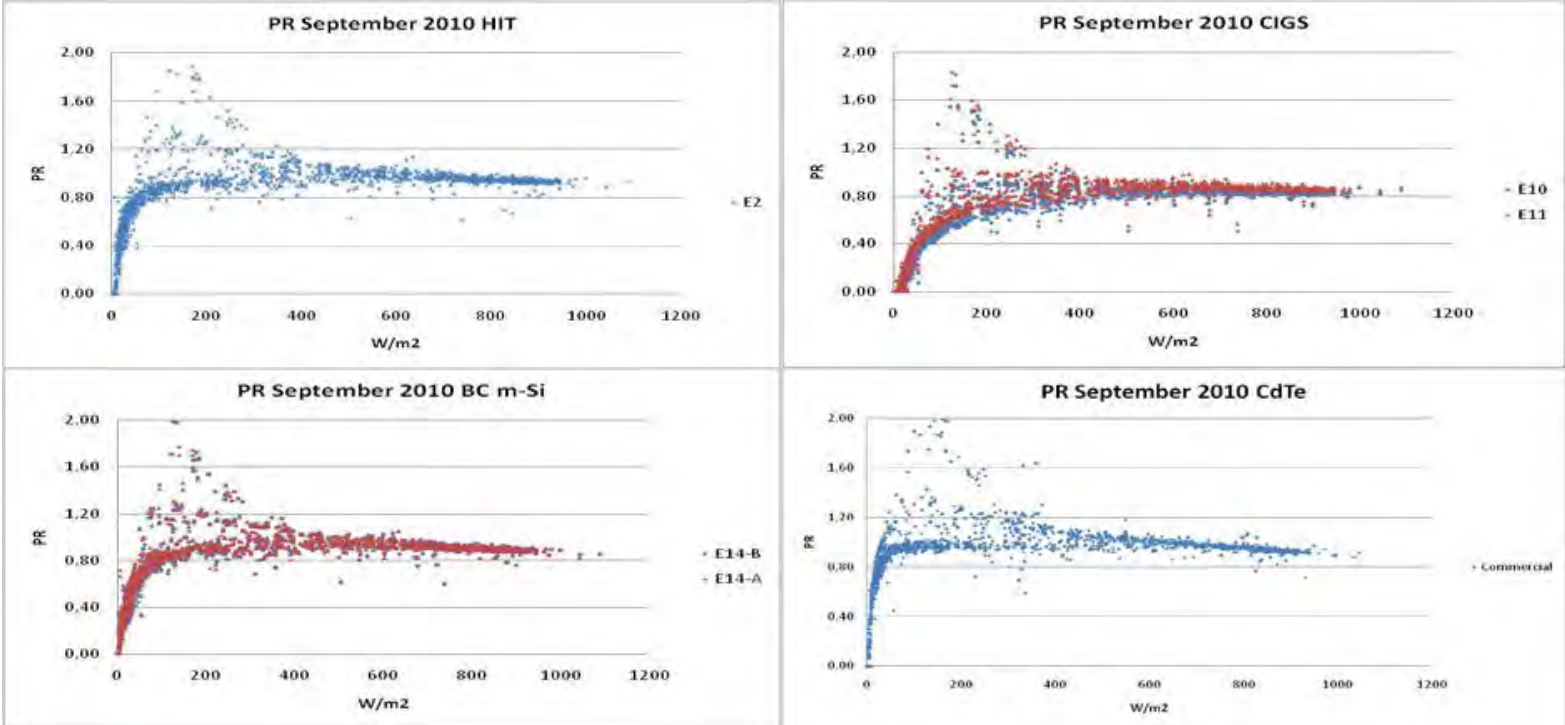

Fig. 1. $P R\left(P_{A C} /\left(P_{p}{ }^{*}\right.\right.$ Irrad. $\left.)\right)$ evaluated every 15 minutes for each day of September 2010 in Bolzano.

The graphs highlight clouds of data at low irradiance levels (mainly between 100 and 200 $\mathrm{W} / \mathrm{m}^{2}$ ), due to the fact that the efficiency of the inverter is not stable for values of irradiance lower than $200 \mathrm{~W} / \mathrm{m}^{2}$. A general high performance and differences in behavior for the same 
technology (as for CIGS, where differences in the trends are visible, especially clear in the month of October) can also be noticed.

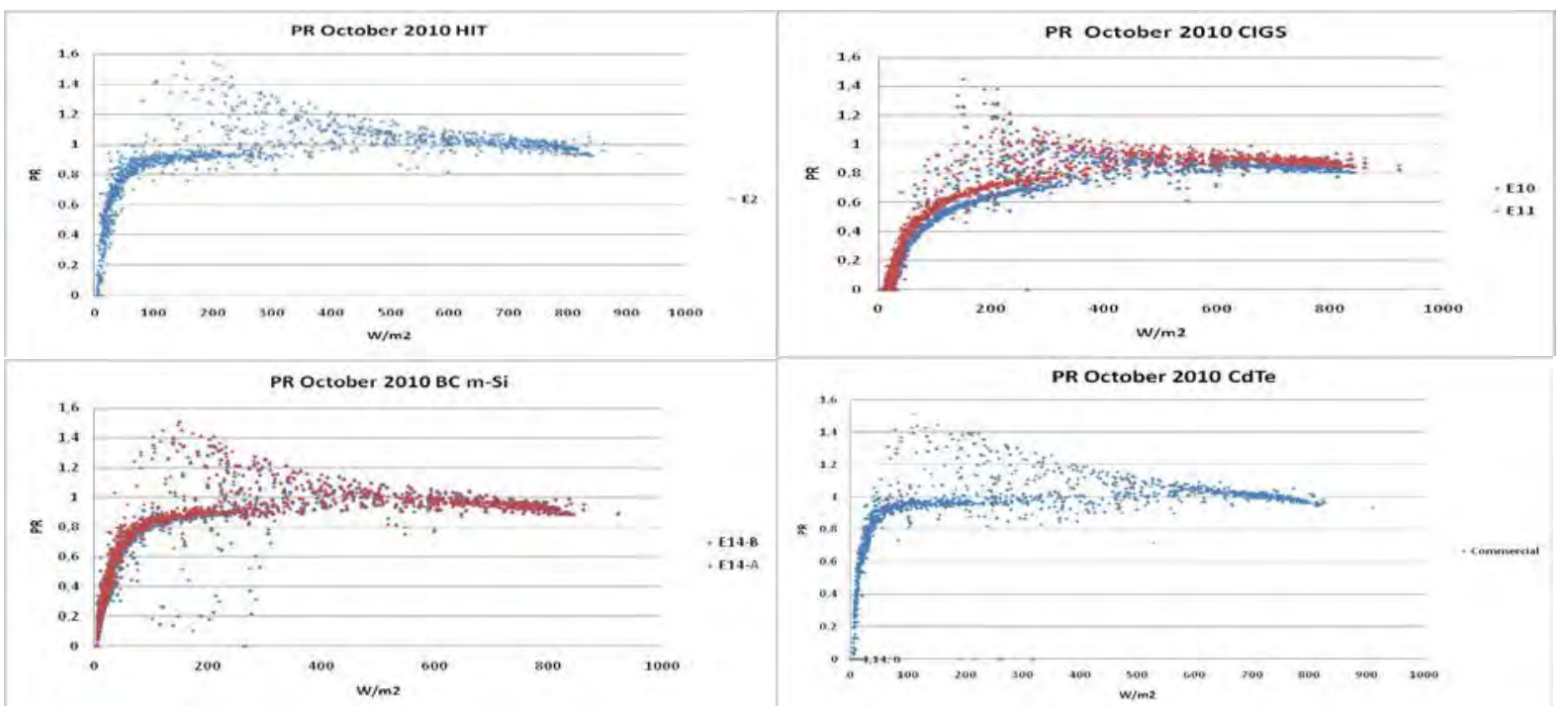

Fig. 2. $P R\left(P_{A C} /\left(P_{p}{ }^{*}\right.\right.$ Irrad. $\left.)\right)$ evaluated every 15 minutes for each day of October 2010 in Bolzano.

\subsection{PV test installation in Milan}

The RSE test installation in Milan has a peak power around $8 \mathrm{kWp}$ and consists of 6 groups of different technologies (polycrystalline silicon, two high-performance monocrystalline silicon, CIS, CdTe and amorphous silicon). The power production is monitored with a custom-made system to evaluate the current and voltage on both DC and AC sides of the inverter.

Table 2. Groups and characteristics in Milan.

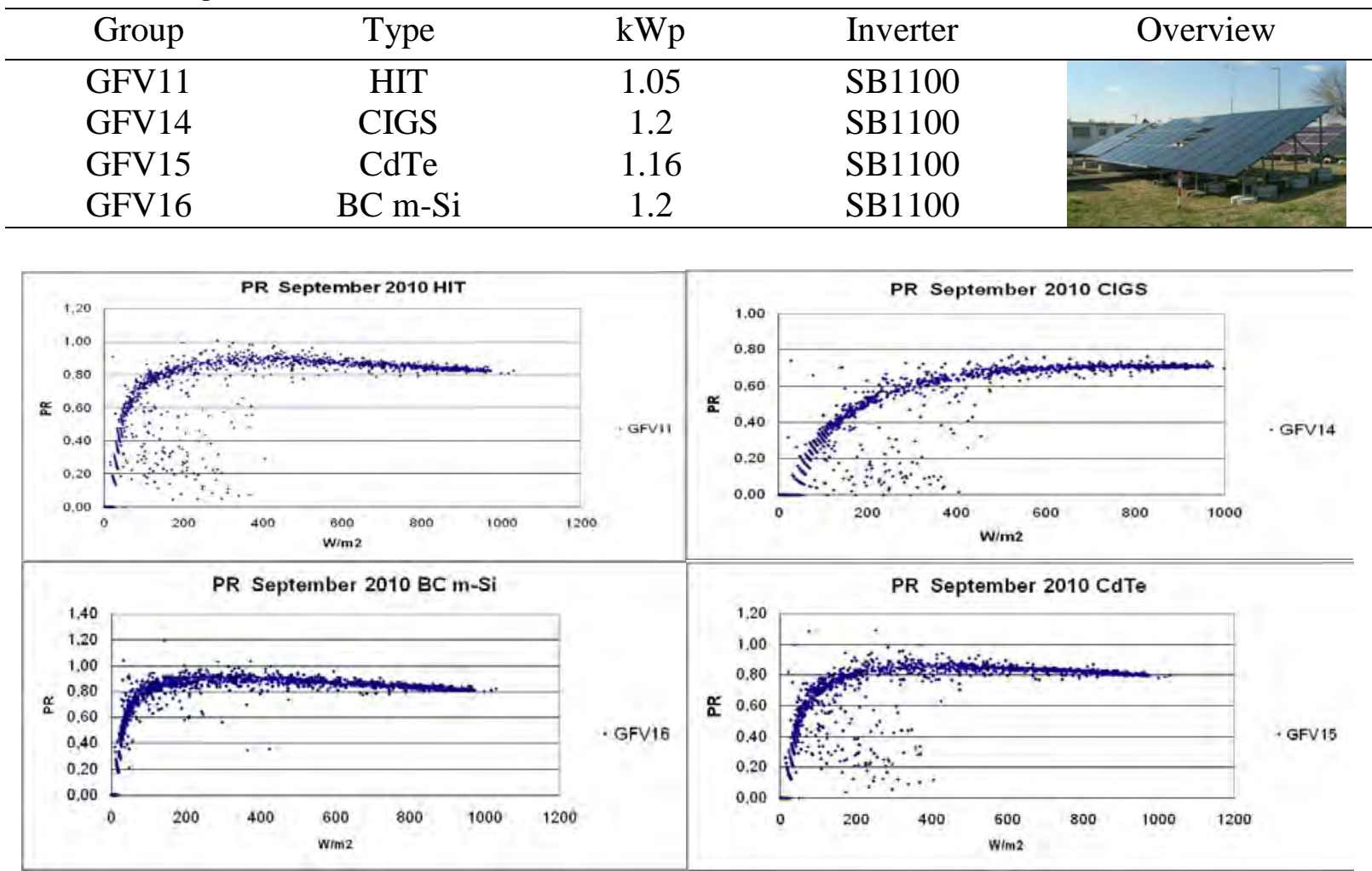

Fig. 3. $P R\left(P_{A C} /\left(P_{p}{ }^{*}\right.\right.$ Irrad. $\left.)\right)$ evaluated every 15 minutes for each day of September 2010 in Milan. 
The groups taken into consideration are listed in Table 2. Figure 3 and 4 show the instantaneous PR for the four PV technologies calculated on a 15-minute base for each day of the month, respectively for September and October 2010.

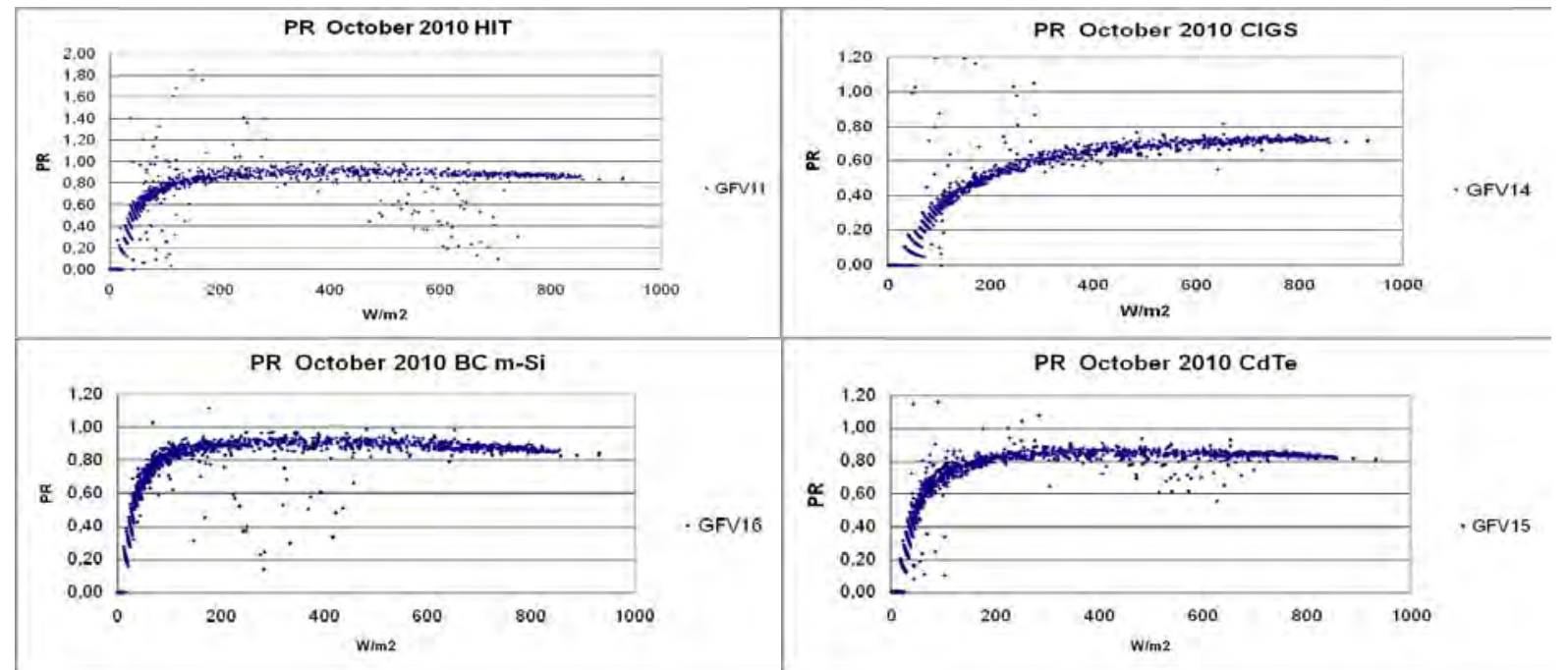

Fig. 4. $P R\left(P_{A C} /\left(P_{p} *\right.\right.$ Irrad. $\left.)\right)$ evaluated every 15 minutes for each day of October 2010 in Milan.

\subsection{PV test installation in Catania}

The RSE test installation in Catania replicates the installation previously described for Milan in all its characteristics. The groups taken into consideration are listed in Table 3. Figure 5 and 6 show the instantaneous PR for the four PV technologies calculated on a 15-minute base for each day of the month, respectively for September and October 2010.

Table 3. Groups and characteristics in Catania.

\begin{tabular}{ccclc}
\hline Group & Type & $\mathrm{kWp}$ & Inverter & Overview \\
\hline GFV1 & HIT & 1.05 & SB1100 & \\
GFV4 & CIGS & 1.2 & SB1100 & \\
GFV5 & CdTe & 1.16 & SB1100 & \\
GFV6 & BC m-Si & 1.2 & SB1100 & \\
\hline
\end{tabular}

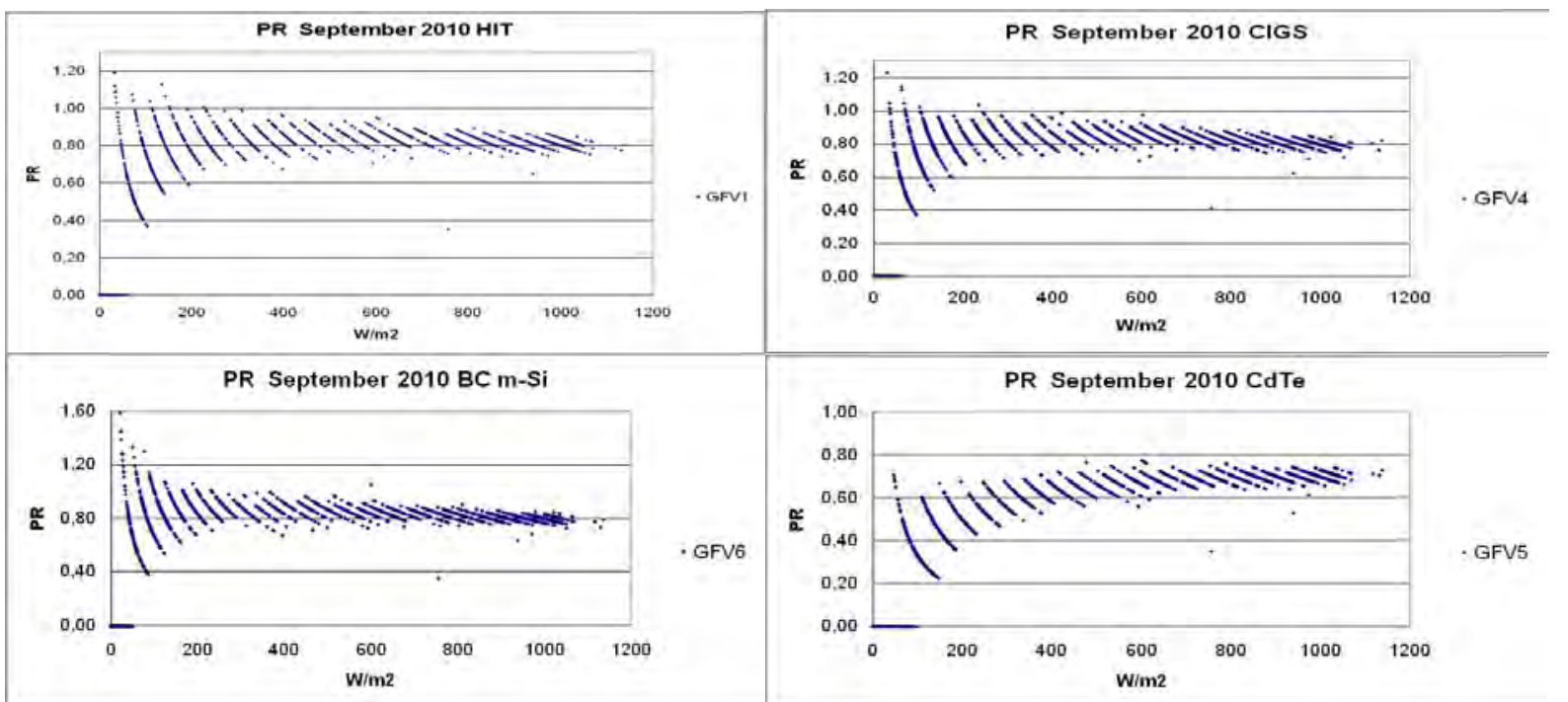

Fig. 5. $P R\left(P_{A C} /\left(P_{p}^{*}\right.\right.$ Irrad. $\left.)\right)$ evaluated every 15 minutes for each day of September 2010 in Catania. 


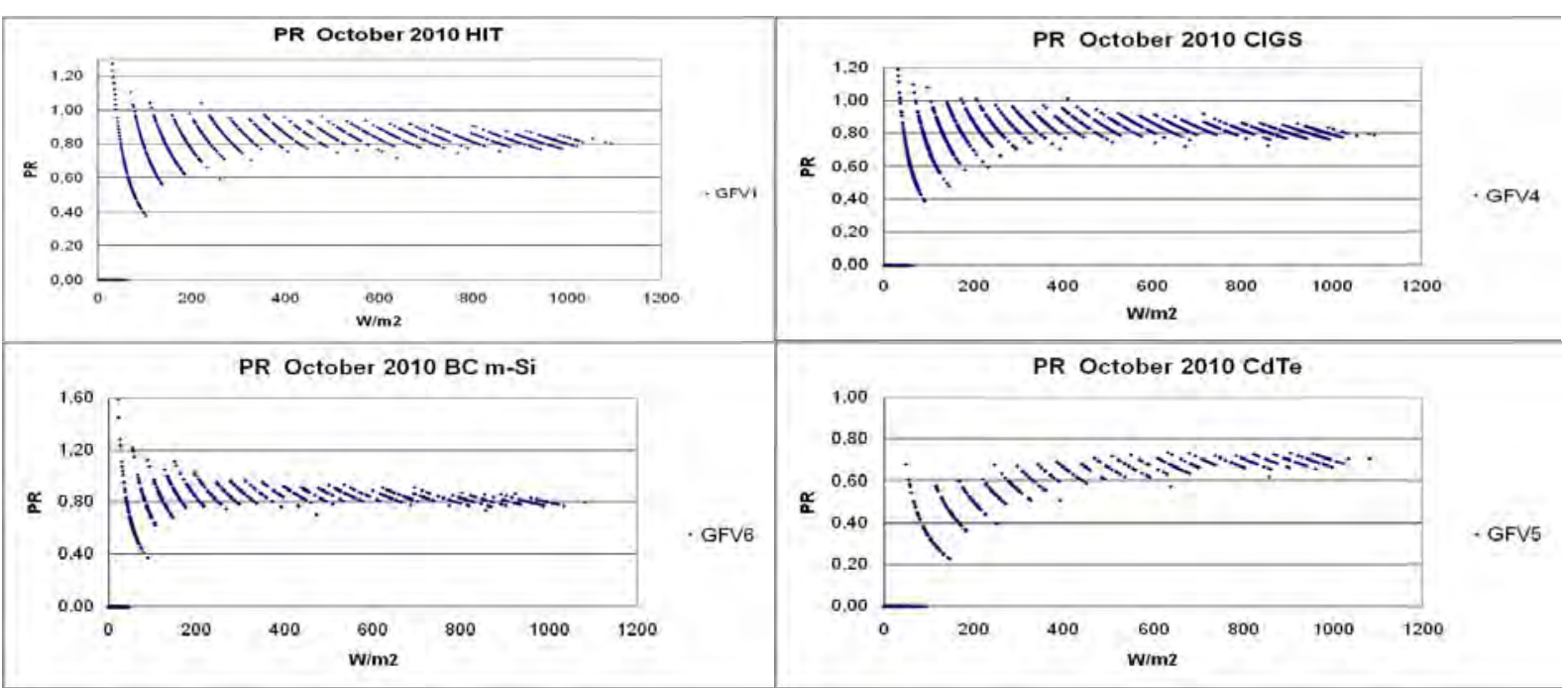

Fig. 6. $P R\left(P_{A C} /\left(P_{p} *\right.\right.$ Irrad. $\left.)\right)$ evaluated every 15 minutes for each day of October 2010 in Catania.

The shape of the plots PR vs Irradiance in Catania is different from the previous considered cases. This is due to different settings of the resolution of the data acquired by the monitoring system, which takes into consideration only two decimal digits in the recorded AC power. The trend of the PR is, for higher irradiances, in line with the previous graphs.

\section{Comparison}

The comparison is conducted according to two indicators: the energy production per $\mathrm{kWp}$ of installed power and the PR, both processed for each month taken into consideration. Moreover, geographical environments and technology-specific behaviors are taken into account while evaluating the results.

\subsection{Methodology}

The calculation of the energy production in $\mathrm{kWh} / \mathrm{kWp}$ is the main element of comparison among the various PV technologies; in fact, using this indicator the irradiance value is omitted as element in the calculation, avoiding the problem rising from mismatch and the difference in the reference devices among the sites. All inverters are from SMA, and each PV technology refers to the same module producer in all cases; anyhow, the issue of accuracy of the data acquisition system, as well as the accuracy in the $\mathrm{kWp}$ value by label, has to be considered. Following the indications of the international standard IEC 61724 [2], the performance of a PV system can be expressed by the PR, that shows the overall effect of losses (due to module temperature, irradiance usage, low components efficiency, faults) on the power output of the plant. The PR is calculated on a monthly base, according to the following ratio:

$$
P R=\frac{Y_{f}}{Y_{r}}
$$

Where $\mathrm{Yf}=\mathrm{E} / \mathrm{P}_{0}$ and $\mathrm{Yr}=\mathrm{H} / \mathrm{G}$, and respectively $\mathrm{E}$ is the energy produced by the $\mathrm{PV}$ system, $\mathrm{P}_{0}$ the installed peak power, $\mathrm{H}$ is the in-plane insolation (in $\mathrm{kWh} / \mathrm{m}^{2}$ ), and $\mathrm{G}$ is the irradiance at STC $\left(1 \mathrm{~kW} / \mathrm{m}^{2}\right)$.

\subsection{Results}

The energy production in kWh reported to the kWp of installed power (specific yield) allows a comparison among groups in the same location, but for different locations the energy 
production has to be always seen in perspective of the irradiance value for the considered period. The values of the monthly global irradiance on $30^{\circ}$ angle, respectively for September and October 2010, in the three considered locations are: Bolzano: $139.60 \mathrm{kWh} / \mathrm{m}^{2}$ and 92.96

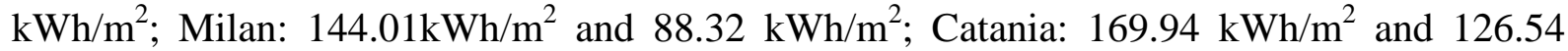
$\mathrm{kWh} / \mathrm{m}^{2}$. Among c-Si technologies, HIT are performing better in Bolzano, while BC $\mathrm{m}$-Si are dominant in Milan and Catania (see Table 4). CdTe modules compete with c-Si mainly in Bolzano and Catania, where the diffuse component of the irradiance is higher for the location characteristics. The production level (in terms of specific yield) of CIGS generally remains lower, with the exception of Milan, where production from CIGS is comparable to HIT. The PR can be compared only by taking into account the correction coefficient from Table 6 .

Table 4. kWh of energy production per kWp of installed power per month, location and technology.

\begin{tabular}{|c|c|c|c|c|c|}
\hline Date & Type & Bolzano & Bolzano & Milan & Catania \\
\hline Sep-10 & BC- & 127.7 (E14-A) & 127.5 (E14-B) & 121.8 & 139.4 \\
\hline Oct-10 & $\mathrm{mSi}$ & 88.7 (E14-A) & 87.3 (E14-B) & 76.5 & 105.5 \\
\hline Sep-10 & \multirow{2}{*}{ HIT } & \multirow{2}{*}{\multicolumn{2}{|c|}{$\begin{array}{c}134.0 \\
93.2\end{array}$}} & 118.6 & 138.5 \\
\hline Oct-10 & & & & 73.9 & 103.7 \\
\hline $\begin{array}{l}\text { Sep-10 } \\
\text { Oct-10 }\end{array}$ & CIGS & $\begin{array}{c}112.5 \text { (E10) } \\
74.3(\mathrm{~F} 10)\end{array}$ & $\begin{array}{l}118.9 \text { (E11) } \\
79.4 \text { (F11) }\end{array}$ & $\begin{array}{c}115.5 \\
721\end{array}$ & $\begin{array}{l}112.6 \\
80.3\end{array}$ \\
\hline $\begin{array}{l}\text { Sep-10 } \\
\text { Oct-10 }\end{array}$ & CdTe & \multicolumn{2}{|c|}{135.6} & $\begin{array}{l}93.3 \\
56.4\end{array}$ & $\begin{array}{l}138.6 \\
103.6\end{array}$ \\
\hline
\end{tabular}

Table 5. PR per month, location and technology.

\begin{tabular}{|c|c|c|c|c|c|}
\hline Date & Type & Bolzano & Bolzano & Milan & Catania \\
\hline Sep-10 & BC- & $0.91(\mathrm{E} 14-\mathrm{A})$ & $0.91(\mathrm{E} 14-\mathrm{B})$ & 0.85 & 0.82 \\
\hline Oct-10 & $\mathrm{mSi}$ & $0.95(\mathrm{E} 14-\mathrm{A})$ & $0.95(\mathrm{E} 14-\mathrm{B})$ & 0.87 & 0.83 \\
\hline Sep-10 & \multirow{2}{*}{ HIT } & \multicolumn{2}{|c|}{0.96} & 0.82 & 0.81 \\
\hline Oct-10 & & \multicolumn{2}{|c|}{1.00} & 0.84 & 0.82 \\
\hline Sep-10 & \multirow{2}{*}{ CIGS } & 0.81 (E10) & 0.85 (E11) & 0.65 & 0.66 \\
\hline Oct-10 & & $0.80(\mathrm{E} 10)$ & 0.85 (E11) & 0.64 & 0.63 \\
\hline Sep-10 & \multirow{2}{*}{ CdTe } & \multicolumn{2}{|c|}{0.98} & 0.80 & 0.82 \\
\hline Oct-10 & & \multicolumn{2}{|c|}{1.00} & 0.82 & 0.81 \\
\hline
\end{tabular}

\section{Validation of the measurement systems}

In order to validate the results of the performance ratio, an attempt is made to compare the DC output power of the various groups with reference to the calculated installed power $(\mathrm{kWp})$. Data sets with an average irradiance level (on 15 minutes) of $900 \mathrm{~W} / \mathrm{m}^{2}$ or higher, and available module temperatures are used to extrapolate the output power to standard reporting conditions of $25^{\circ} \mathrm{C}$ and $1000 \mathrm{~W} / \mathrm{m}^{2}$ irradiance level (excluding correction to airmass 1.5 global spectral irradiance). The values of the temperature coefficients for $\mathrm{P}_{\max }$ used for the different PV technologies are as from [3] and are listed in Table 6. Concerning Bolzano, remarkable is the difference between two identical CIGS groups. The difference of $4 \%$ is also noted in Fig. 1 and 2. This is caused partially by the inverter data acquisition. Both BC m-Si groups show an overestimation in power of nearly $10 \%$, but the difference between the two systems is negligible $(<0.5 \%)$. Also HIT technology shows an overestimation in power, which can be attributed to the mismatch in the spectral responsivity between the reference detector and the modules. This is valid for both silicon-based technologies. 
Table 6. Correction coefficient for PR values.

\begin{tabular}{|c|c|c|c|c|c|c|}
\hline Technology & $\mathrm{BC} \mathrm{m}-\mathrm{Si}$ & $\mathrm{BC} \mathrm{m}-\mathrm{Si}$ & HIT & CIGS & CIGS & CdTe \\
\hline TC_Pm [\%/ $\left./{ }^{\circ} \mathrm{C}\right]$ & -0.45 & -0.45 & -0.50 & -0.36 & -0.36 & -0.21 \\
\hline Location & \multicolumn{6}{|c|}{ Bolzano } \\
\hline $\begin{array}{c}\text { Average DC_STC } \\
{[\mathrm{kWp}]}\end{array}$ & 1.30 & 1.30 & 4.16 & 1.10 & 1.15 & 9.28 \\
\hline $\begin{array}{c}\text { Standard deviation } \\
\text { DC_STC [kWp] }\end{array}$ & 0.03 & 0.03 & 0.12 & 0.03 & 0.02 & 0.13 \\
\hline Difference [\%] & $\begin{array}{c}7.9 \\
(\mathrm{E} 14-\mathrm{A})\end{array}$ & $\begin{array}{c}8.3 \\
(\mathrm{E} 14-\mathrm{B})\end{array}$ & 7.6 & $\begin{array}{c}\mathbf{- 1 . 5} \\
(\mathrm{E} 10)\end{array}$ & $\begin{array}{c}2.5 \\
(\mathrm{E} 11)\end{array}$ & -0.2 \\
\hline Location & \multicolumn{6}{|c|}{ Milan } \\
\hline $\begin{array}{c}\text { Average DC_STC } \\
{[\mathrm{kWp}]}\end{array}$ & \multicolumn{2}{|c|}{1.16} & 1.03 & \multicolumn{2}{|c|}{1.01} & 1.17 \\
\hline $\begin{array}{c}\text { Standard deviation } \\
\text { DC_STC [kWp] }\end{array}$ & \multicolumn{2}{|c|}{0.01} & 0.01 & \multicolumn{2}{|c|}{0.01} & 0.01 \\
\hline Difference [\%] & \multicolumn{2}{|c|}{-3.2} & -1.9 & \multicolumn{2}{|c|}{-16.0} & 0.5 \\
\hline Location & \multicolumn{6}{|c|}{ Catania } \\
\hline $\begin{array}{c}\text { Average DC_STC } \\
{[\mathrm{kWp}]}\end{array}$ & \multicolumn{2}{|c|}{1.14} & 1.00 & \multicolumn{2}{|c|}{1.10} & 1.05 \\
\hline $\begin{array}{l}\text { Standard deviation } \\
\text { DC_STC [kWp] }\end{array}$ & \multicolumn{2}{|c|}{0.02} & 0.02 & \multicolumn{2}{|c|}{0.03} & 0.02 \\
\hline Difference [\%] & \multicolumn{2}{|c|}{-5.0} & -4.7 & \multicolumn{2}{|c|}{-8.7} & -9.3 \\
\hline
\end{tabular}

For Milan, the difference between calculated power at $1000 \mathrm{~W} / \mathrm{m}^{2}$ and $25^{\circ} \mathrm{C}$ and the measured DC power for the CIGS is very large, and cannot be justified by the spectral mismatch between $\mathrm{C}-\mathrm{Si}$ reference detector and the spectral responsivity of the CIGS material. The differences of the BC m-Si and HIT materials can be attributed to spectral mismatch. The very small difference of the CdTe is also remarkable, as the spectral mismatch between c-Si and CdTe is normally around $8-10 \%$. In Catania, it must be considered that the module temperatures are higher than for the two northern locations. The $-8.7 \%$ difference for CIGS can be attributed to spectral mismatch, as well as the -9.3 for CdTe. The values for BC m-Si and HIT can originate from the temperature (as correction for $\mathrm{T}$ is more dominant than for the locations of Milan and Bolzano), as well as being influenced by the spectral mismatch.

As general remarks for the reference detector, guidelines are given in IEC 61724 [2] and require an irradiance reference detector with an accuracy better than $5 \%$. As for the technologies CIGS, HIT, BC m-Si, a c-Si reference detector (as used by RSE in Milan and Catania) would reduce the effect of spectral mismatch. A rough estimation of $\pm 7 \%$ spectral mismatch for the above mentioned technologies should be taken in consideration for the Bolzano data (as an a-Si reference detector is used). For CdTe the spectral mismatch is estimated around $\pm 3 \%$. These data will be used in the uncertainty calculation table. Some assumptions are made to estimate the overall uncertainty of the final PR value. For all uncertainty components, a " $\mathrm{B}$ " type standard uncertainty and a " $\mathrm{R}$ " (rectangular) distribution is assumed. Therefore the reduction factor is $\sqrt{3}$. The total index of uncertainty that is reported is calculated as the square root of the sum of the squares of the individual contributions. The uncertainties given in Table 7 are with a coverage factor $(\mathrm{k})$ of 2 . With a Gaussian probability distribution, this gives a confidence level of $95 \%$. 
Table 7. Uncertainty values for the different PV technologies in the three considered locations.

\begin{tabular}{lcccccc}
\hline & \multicolumn{3}{c}{ Location } & & \multicolumn{2}{c}{$\begin{array}{c}\text { Estimated } \\
\text { Uncertainty }\end{array}$} \\
\hline & \multicolumn{2}{c}{ Bolzano } & Milan\&Catania & TF & Si \\
{$[\%]$} & {$[\%]$} \\
\hline Standard uncertainty component & TF & Si & TF & Si & & \\
Stability of Reference Device & 1.73 & 1.73 & 0.58 & 0.58 & 3 & 1 \\
Calibration of reference device & 4.62 & 4.62 & 1.44 & 1.44 & 8 & 2.5 \\
Spectral Mismatch & 1.73 & 4.04 & 4.04 & 1.73 & 3 & 7 \\
Irradiance DAS & 0.00 & 0.00 & 0.58 & 0.58 & 0 & 1 \\
Inverter / DAS & 0.58 & 0.58 & 0.58 & 0.58 & 1 & 1 \\
Installed power & 2.31 & 1.15 & 2.31 & 1.15 & 4 & 2 \\
Combined standard uncertainty & $\mathbf{5 . 7}$ & $\mathbf{6 . 5}$ & $\mathbf{5 . 0}$ & $\mathbf{2 . 7}$ & & \\
Expanded standard uncertainty k=2 & $\mathbf{1 1 . 5}$ & $\mathbf{1 3 . 0}$ & $\mathbf{9 . 9}$ & $\mathbf{5 . 4}$ & & \\
\hline
\end{tabular}

\section{Conclusions}

The analysis shows a relevant impact of the geographical location (temperature, irradiance components) on the performance of selected PV technologies. In facts it clearly appears that certain technologies have a better energy production compared to others in the same location. Nevertheless, the importance of the monitoring devices and system components results clear while evaluating the performance. Commercial-type monitoring systems need improvements in quality and reference devices need regular maintenance activity. It is also important to match the module technology with an appropriate reference device. This issue becomes relevant when evaluating the PR. The monitoring system in Bolzano is under way to be improved to reduce data uncertainty and a collaboration with RSE is set to install additional monitoring devices on the DC and AC sides of the inverters for selected groups.

\section{Acknoledgements}

The Authors from EURAC Research would like to thank the European Regional Development Fund (ERDF) for co-financing the PV ABD project.

The Authors from RSE would like to acknowledge that their work has been financed by the Research Fund for the Italian Electrical System under the Contract Agreement between RSE (formerly known as ERSE) and the Ministry of Economic Development - General Directorate for Nuclear Energy, Renewable Energy and Energy Efficiency stipulated on July 29, 2009 in compliance with the Decree of March 19, 2009.

\section{References}

[1] H. Ossenbrink, K.A. Münzer, "The ESTIsensor - A New Reference Cell for Monitoring of PV Plant Performance”, 11th European Photovoltaic Solar Energy Conference and Exhibition, Montreux, Switzerland, 1992.

[2] International standard IEC 61724:1998 "Photovoltaic System Performance Monitoring Guidelines for Measurement, Data Exchange and Analysis”.

[3] A.Virtuani, D. Pavanello, G. Friesen, "Overview of Temperature Coefficients of Different Thin Film Photovoltaic Technologies”, 25 ${ }^{\text {th }}$ EU PV SEC, 6-10 September 2010, Valencia, Spain. 